\title{
OS 25 ANOS DA SOCIEDADE BRASILEIRA DE AUTOMÁTICA
}

\author{
Plinio de Lauro Castrucci* \\ pcastruc@uol.com.br
}

\author{
Eugenius Kaszkurewicz ${ }^{\dagger}$ \\ eugenius@adc. coppe.ufrj.br
}

*EPUSP - Escola Politécnica

Universidade de São Paulo, São Paulo.

${ }^{\dagger}$ COPPE - UFRJ

Universidade Federal do Rio de Janeiro, Rio de Janeiro.

\begin{abstract}
As the Sociedade Brasileira de Automática completed 25 years of existence during the CBA2000, the authors present a short resumé of its activities after 1986, since the previous ones have been dealt with in an article of the nr. 1 vol. 1 of this periodical; they also reproduce the speech pronounced by one of the authors at that congress banquet; in the last section, the future of SBA is discussed and 6 themes, with suggestions to consideration by the community.
\end{abstract}

\section{RESUMO}

Tendo a Sociedade Brasileira de Automática completado 25 anos durante o CBA2000, os autores procuram neste artigo resumir as atividades posteriores a 1986, dado que as atividades anteriores foram apresentadas no no.1 vol. 1 desta revista; reproduzem também o discurso que um dos autores proferiu durante o banquete de encerramento do CBA2000; e na última seção, discutem o futuro da SBA, apresentando seis temas, com sugestões para consideração da comunidade.

\section{INTRODUÇÃO}

Fundada em cinco de junho de mil novecentos e setenta e cinco, em memorável reunião que contou com a presença de sessenta e oito especialistas brasileiros, a Sociedade Brasileira de Automática comemorou seu vi- gésimo quinto aniversário durante o XIII Congresso, o CBA2000, em Florianópolis.

O Artigo $4^{\circ}$. de seus Estatutos a define como "Sociedade de âmbito nacional, com objetivo primordial de promover a ciência e a tecnologia de controle automático no seu mais amplo sentido, em todos os sistemas, sejam eles físicos, biológicos, sociais, econômicos, no Brasil.".

Sua história tem sido de persistente progresso quantitativo, aliado a uma admirável constância de qualidade intelectual: o número de associados atinge a marca das cinco centenas; treze congressos bianuais realizaram-se, com idênticos e rigorosos critérios e métodos para seleção de trabalhos; publicaram-se anais de todos os congressos, com centenas de artigos. A SBA tem participado de muitas reuniões setoriais e regionais e tem mantido com regularidade a publicação da revista Controle e Automação, sob estritos padrões científicos.

O Prof. Dr. Walter Celso de Lima registrou muito bem os primeiros dez anos da SBA, em artigo do Vol.1 No.1 da Revista; na primeira seção do presente artigo os autores resumem as atividades posteriores a 1986. Outro objetivo do artigo é discutir o futuro da SBA.

\section{ATIVIDADES}

A partir de 1986 foram assim constituídas as Diretorias da SBA, descritas na seqüência de Presidente, Vicepresidente, Secretário e Tesoureiro: 
1987-89 Hermano M F Tavares - José A M Felippe de Souza - Fernando A Campos Gomide - Paulo A Valente

1989-91 Ronaldo Tadeu Pena - Eugenius Kaszkurewicz - Selênio Rocha Silva - Marcio Lages Siqueira

1991-93 Pedro Magalhães Guimarães Ferreira - Antônio J Alves Simões Costa - Paulo Leo Manassi Osório - Ricardo Tanscheit

1993-95 Antônio J Alves Simões Costa - Edson de Paula Ferreira - Vitório Bruno Mazzola - Edson Roberto de Pieri

1995-97 Edson de Paula Ferreira - Márcio R Rillo Mário Sarcinelli Filho - Celso José Munaro

1997-99 Márcio R Rillo - Luiz Pereira Caloba - Paulo Eigi Miyagi - Ricardo P Marques

1999-2002 Luiz Pereira Caloba - Fernando A C Gomide - Fernando G Vianna Resende Jr. - Luís G Barbosa Rolim

2002 Edison Roberto Cabral da Silva - Takashi Yoneyama - Antonio Marcus Nogueira Lima - José Sérgio da Rocha Neto

A direção de uma entidade comunitária e democrática como a SBA não poderia ser bem conduzida sem a contribuição dos seus Conselhos Técnicos e Administrativos, cuja composição está relatada no Anexo. Também lá estão, por sua relevância, os editores da revista Controle e Automação.

Os Congressos e seus Presidentes, a partir de 1986, foram:

1986 Belo Horizonte - Ronaldo Tadeu Pena

1988 S. José dos Campos - José A. M. Felippe de Souza

1990 Belém - Jurandir Nascimento Garcez

1992 Vitória - Edson de Paula Ferreira

1994 Rio de Janeiro - Pedro M Guimarães Ferreira

1996 S. Paulo - Plinio B L Castrucci

1998 Uberlândia - João Batista Vieira Jr.

2000 Florianópolis - Augusto Bruciapaglia

Dentre os outros eventos, cumpre destacar por sua importância o IFAC Symposium on Robust Control Design, realizado no Rio de Janeiro em 1994 e presidido pelo Prof. Pedro M Guimarães Ferreira.

\section{CELEBRAÇÃO DO 25․ ANIVERSÁRIO, DURANTE O XIII CBA}

"Professor Augusto Bruciapaglia, Presidente do CBA2000

Professor Luiz Caloba, Presidente da Sociedade Brasileira de Automática

Professor Simões Costa, Presidente do Comitê Técnico do CBA2000

Senhoras e senhores

Companheiros

Completar 25 anos de existência é sem dúvida um feito que exige celebração condigna. Quando o Prof. Caloba me honrou com o convite para dizer algumas palavras, logo pensei na flagrante injustiça de ter sido eu, tantas vezes, aquí homenageado. Ocorreu-me então falar dos outros importantes colaboradores da Sociedade, dos fundadores e das circunstâncias; mas seria de justiça mencionar também os presidentes; depois, pensei, não seria justo omitir os diretores, principalmente os mágicos tesoureiros; e os conselheiros; e os editores da Revista; e os autores...Logo porém concluí: é impossível em tal ocasião mencioná-los um por um.

De fato, a SBA tem funcionado como uma imensa corrente de boa vontade, de solidariedade e de competência, audaciosamente percorrendo este imenso País. E em uma corrente, é por acaso possível considerar um elo mais importante que outro ? Claro que não. O que cabe é, assim como dividimos entre todos os trabalhos, dividirmos a gloria, o orgulho pelo resultado obtido.

Acho que o momento é também de reflexão: o que temos sido? o que somos? para onde vamos?

Temos de fato sido uma comunidade de intensa afinidade intelectual, que soube sobreviver às flutuações ambientais; iniciou-se numa década em que se desenhava o Brasil-Potência, por meio de alvos claramente definidos a realização nacional de linhas metroviárias, de locomotivas, de navios, de computadores -, todos dependentes de controle; enfrentou a freiada geral da indústria na década de 80, mas participou de alguns desenvolvimentos notáveis - o enriquecimento do urânio, os progressos em prospeção do petróleo -; manteve a qualidade do ensino e da pesquisa, as sementes do futuro, na infeliz conjuntura da última década. Pelo menos provamos que somos controladores pois enfrentamos muito bem as perturbações...

Esta sociedade tem sido muito sábia, não apenas no sentido científico mas no da sabedoria de vida.

$\mathrm{Na}$ fundação, nossa grande preocupação era que a SBA ficasse estigmatizada pela "propriedade" do grupo X ou 
Y, ou da região A ou B; felizmente isso não ocorreu, talvez por causa dos estatutos que impedem segunda reeleiçào da mesma diretoria, talvez porque a meta de percorrer o País com seus CBA's exige a delegação de responsabilidades...

Mas a SBA, pela visão especial dos seus Conselhos Técnico-Administrativos, sempre soube adaptar-se. Por exemplo, acolheu duas preciosas comunidades, a dos Sistemas de Potência e a da Eletrônica de Potência, com os quais o núcleo inicial de "controleiros" estabeleceu extraordinária simbiose.

Tivemos, é natural, insucessos relativos: muitos de nós desejávamos uma forte interaçào com a indústria e as empresas de engenharia, enfim com nossos ex-alunos na sua vida prática. Tem sido difícil que eles participem dos CBA's no seu formato predominante, o qual é no entanto essencial para a qualidade e o prestígio nacional da organização; a dificuldade é compreensível pois persistem: uma crônica escassez de capital nas empresas nacionais, freqüentes "stop and go" na macroeconomia, grande importação de tecnologias de processo, todos fatores que não deixam qualquer folga de energia ou de tempo para os colegas que labutam nas empresas. A situação é muitíssimo diferente daquela dos USA de 1930, que eram ultra-protecionistas de sua indústria (impostos de importação na faixa dos $60 \%$ !), e onde os Bell Labs podiam manter, em seus quadros, teóricos como Nycquist e Bode...

Tentando definir o que hoje somos, eu assim resumiria: uma comunidade intelectual coesa mas aberta, dotada de uma notável, e estável, vocação científica. Digo cientifica e não tecnológica ou de engenharia, porque estamos sempre explorando os limites de desempenho possível, dados pelas leis da Natureza; para provar, basta assistir a muitas das nossas sessões técnicas. Assim mantemos a tradição das origens, dos teoremas de um Bode, das matemáticas de um Wiener, de um Kalman, de um Liapunov.

Somos já uma frondosa árvore institucional, de forte personalidade, com três ramos básicos, controle, sistemas de energia elétrica e eletrônica de potência. Dizem alguns psicólogos que Três é o número da dinâmica, pois nunca ocorrem impasses nas decisões; que Quatro é o número da perfeição...

Existe na SBA um mistério a desvendar: o computador é a mais automática das máquinas do século XX, e é o mais flexível dos componentes de qualquer sistema automático; no entanto são muito pequenas nossas atividades nesta área, ou pelo menos em software de tempo real, fundamental em controle. Não seria a hora e a vez de preenchermos esse "gap", de ampliarmos o competente núcleo de colegas que já pesquisam em controle de sistemas a eventos e de manufatura, formando a quarta perna da SBA, aquela que completaria a perfeição? Quem sabe assim atrairíamos pesquisadores da matemática aplicada e da engenharia de computação, e ampliaríamos o mercado de trabalho para nossos alunos.

O que queremos ser? Certamente, desejamos aumentar nossa contribuição à ciência e à tecnologia, ao bem-estar do País; desejamos crescer com qualidade. O difícil é escolher o caminho e o próximo passo.

Olhando para 25 anos atrás, o que fizemos foi sonhar bem alto; e o sonho concretizou-se. O poeta dizia que navegar é preciso; eu diria que sonhar é preciso, sempre, e de preferência pelos olhos dos mais jovens. Portanto, "mãos à obra, isto é, ao sonho"...

E para concluir, um brinde aos 25 anos passados e aos seus sucessos, graças a Deus!

E um brinde às vitórias dos próximos 25 anos!"

\section{O FUTURO}

Por influência da nossa formação de "controlistas", não podemos deixar de abordar o tema do futuro da SBA com base em uma formulação sistêmica, começando pelo questionamento de quais seriam os estados, o atual e o desejável, em um horizonte de, digamos, dez anos.

Essa perspectiva certamente nos remete a recorrer às nossas "referências" ou aos nossos objetivos. Os estatutos da SBA a estabelecem "com o objetivo primordial de promover a ciência e a tecnologia de controle automático no seu mais amplo sentido, em todos os sistemas".

Também sabemos que, além dos estados inicial e final, é preciso avaliar o ambiente no qual está imerso o processo, e as perturbações conseqüentes; no caso da tecnologia da automação no Brasil, o ambiente é todo o contexto macroeconômico e técnico, nacional e mundial, e seus reflexos no mercado de engenharia, na vida acadêmica e nos desafios científicos. A característica fundamental desse ambiente é indubitavelmente a mudança, a evolução constante, o que nos leva a adotar o paradigma adaptativo dos "controlistas", e portanto a concentrar as considerações sobre futuro, apenas no curto prazo.

a) O mundo passa por um já longo período de superabundância de produtos industrializados, produzidos por poucas empresas, que contam com enorme vantagem competitiva: a) pelo comércio e pela comunicação internacionais; b) pela grande escala de 
produção; c) pela mão de obra, barata em países asiáticos ou subempregada em outros países. O quadro está longe de ser alterado e traz como conseqüência que a fabricação de hardware com tecnologia própria no País não é meta interessante. Convém lembrar que a SBA representa pessoas e o interesse geral da sociedade brasileira, que o importante é avaliar se e como os engenheiros de controle e automação estão sendo úteis e requisitados. Responderíamos pela afirmativa, pois a qualidade de vida e a produtividade do País dependem de engenheiros bem aplicarem os tais hardwares ( não de fabricá-los). Exemplificando: um PLC que custa US $\$ 2.000,00$ pode controlar um processo industrial que produz (digamos) US $\$ 20.000,00$ por mês, e aumentar o ganho da empresa em $1 \%$ do faturamento; isto significa que o investimento em hardware será devolvido à indústria em meros 10 meses! Sem contar outros ganhos como a melhoria da qualidade. E qual é, além do hardware, o elemento necessário? É o engenheiro de automação, no tempo e no local certo - o que aliás quer dizer, por toda parte deste imenso país. Haja portanto ensino de automação e SBA!

b) Neste aspecto, tomemos por premissa o fato de que as matérias lecionadas nos cursos de graduação e pós-graduação são parte importante no desenvolvimento da automação no nosso país. Colocamos abaixo algumas reflexões para futuras discussões na nossa Sociedade.

Como sabemos, as pós-graduações nas Universidades do país adquiriram um "status" importante e como conseqüência a pesquisa tem sido valorizada; na área de automação não foi diferente, e várias pósgraduações foram consolidadas e atingiram padrões internacionais. Cabe então perguntarmos se a graduação estaria recebendo o mesmo grau de atenção; estariam os atuais currículos adequados à demanda tecnológica corrente no mercado de trabalho, ou estaria sendo ensinado um determinado conjunto de disciplinas, atualizado tão somente a partir da pósgraduação e da pesquisa? Este questionamento nos ocorre a partir do perfil das publicações nos últimos CBA's e sobre ele devemos refletir.

Dado que a Engenharia de Controle e Automação é, graças ao esforço de colegas da SBA, uma habilitação atualmente reconhecida pelo MEC, a nossa responsabilidade na formação de engenheiros de automação modernos passa a ser ainda maior. Neste aspecto entendemos que a SBA deveria promover simpósio dedicado à discussão do ensino de automação nos cursos de graduação. c) Considere-se o exemplo, citado, de que grupos dedicados aos sistemas de energia elétrica e aos sistemas de potência se integraram perfeitamente à SBA e, como conseqüência, dinamizaram a vida da sociedade, pois esta passou a comunicar-se com áreas de interesse coletivo como é a energética. O "crossover" fez sentido porque representou, por analogia, que a automática aproximar-se do tal "objeto a ser controlado".

\section{Como promover novos "crossovers"?}

Certamente uma das atividades mais significativas da SBA são os seus congressos bianuais, os CBAs. Neles, apesar dos esforços de muitos, percebe-se uma certa tendência à estabilização em um determinado patamar e a uma participação significativamente majoritária de centros de pesquisas e de universidades. Buscando inspiração nos algoritmos genéticos, seria adequado provocar alguns novos "crossovers" ou até "mutações".

Uma idéia seria a de promover conferências conjuntas com outras sociedades, como as de telecomunicações (SBT); de computação (SBC); de matemática aplicada (SBMAC); de mecânica (ABCM), de engenharia química (ABEQ), de biotecnologia, e outras. Na realidade essas conferências deveriam ser do tipo de "Joint Conferences" como eram as promovidas pela "American Control Systems Society".

d) Outra questão fundamental é a participação de empresas e industrias, tanto nos eventos quanto na própria SBA. Na realidade são poucos os sócios entidades ligados ao setor industrial ou empresarial e esse é um indicador preocupante. Olhando, novamente, o contexto macroeconômico, facilmente se conclui que as empresas mais desejáveis como sócios são as indústrias de processo, "clientes" de automação, as de engenharia e as fornecedoras internacionais de hardware de automação. Todas estão interessadas na disponibilidade de tecnologia e de especialistas.

No aspecto de se promover uma maior interação com o setor industrial, "simpósios de aplicações na indústria" como aquele organizado no CBA 96 na USP deveriam ser incluídas nos futuros CBAs.

Na mesma direção de interesse, entidades como a IFAC (uma de nossas referências) têm convidado altos executivos de empresas como Ford, General Motors, dentre outras, para palestras plenárias. Nestas plenárias são mostradas necessidades tecnológicas atuais e locais, desafios tecnológicos e científicos importantes para a comunidade. Seria interessante 
que os organizadores dos próximos CBAs levassem esta sugestão em conta.

e) Uma outra frente em que a SBA tem sido pouco ativa também consta dos estatutos da SBA: "incentivar os poderes públicos e instituições particulares competentes a fornecerem recursos e tomarem medidas que contribuam para o desenvolvimento da Automática no país".

O MCT (Ministério da Ciência e Tecnologia) lançou recentemente os chamados fundos setoriais para diferentes áreas de infra-estrutura: Petróleo, Energia Elétrica, Transportes, Aeroespacial, Telecomunicações, dentre outras. Sociedades científicas têm atuado junto a órgãos do governo para que esses fundos setoriais sejam regulamentados adequadamente. A SBA deveria participar dessa atuação, no sentido de destacar a importância do papel da automação nessas diferentes áreas..

f) Um último tema para possível ação da SBA é mais amplo e tem a ver com a própria ética de nossa profissão: o estudo do modelo quantitativo que liga automação ao desemprego e à economia em geral. Parece-nos que falta um modelamento completo e, mais ainda, no ambiente nacional: tomando por base alguns processos típicos de automação (manufatura, banco, indústria de base), qual seria o balanço completo de custos e benefícios para a sociedade? Há que considerar a economia das empresas, a economia dos clientes pela redução dos preços dos produtos, o desemprego e o emprego através do efeito conseqüente sobre a massa salarial, o aumento dos impostos arrecadados por causa do aumento dos lucros e das vendas, etc..

Nossa sugestão é que este seja um tema de Mesa Redonda no próximo CBA, e quem sabe objeto de atenção de algum grupo de pesquisadores controlistas.

\section{CONCLUSÃO}

Pelo acima exposto, os desafios e as referências colocadas para o futuro da SBA, na realidade já foram previstos nos seus estatutos, por ocasião da sua fundação. Basta recuperá-los e, no jargão da especialidade, atuar no sistema para que aquelas referências sejam atingidas em tempo mínimo, com eficiência máxima e com robustez. Assim progrediremos em termos de penetração e crédito social, tanto no meio acadêmico como no empresarial do país.

\section{ANEXO}

\section{Conselhos Técnicos e Administrativos:}

1988-90

Jacques Szczupak - José Cláudio Geromel - Jurandir Nascimento Garcez - Henrique Pacca Loureiro Luna Liu Hsu - Manuel de Jesus Mendes

1990-92

Benjamin Rodrigues de Menezes - Edson de Paula Ferreira - Hermano Medeiros F. Tavares - Jurandir Nascimento Garcez - Pedro Magalhães Guimarães Ferreira Walter Celso de Lima

1992-94

Atair Rios Neto - Celso Pascoli Bottura - Liu Hsu Luís Pereira Caloba - Ronaldo Tadeu Penna - Secundino Soares Filho

1994-96

Amilton Salles Garcia - José Cláudio Geromel - Osvaldo Luís do Valle Costa - Pedro Magalhães Guimarães Ferreira - Selênio Rocha e Silva - Wellington Santos Mota

$1996-98$

Carla Cisar Martins - Edson Roberto de Pieri - Luís Pereira Caloba - Pedro Magalhães Guimarães Ferreira Ricardo Tanscheidt - Vitório Bruno Mazzola

1998-2000

Aldayr Dantas de Araujo - Edson Roberto de Pieri Fábio Gonçalves Jota - João Bosco Ribeiro do Val Mário Sarcinelli Filho - Ricardo Tanscheit

2000-2002

Antonio Marcus N. Lima - Augusto Bruciapaglia - Edson H. Watanabe - Fabio Jota - Mário Sarcinelli - Ricardo Paulino

\section{Editores de Controle e Automação:}

Wagner Caradori do Amaral 1986-89

José Cláudio Geromel 1989-91

Rafael Santos Mendes 1992-96

Osvaldo Luís do Valle Costa 1996-2000

João Bosco Ribeiro do Val 2000- 